\title{
AVALIAÇÃO DA ATIVIDADE DAS ENZIMAS PECTINA METILESTERASE E $\beta$-GALACTOSIDASE EM MAMÕES cv. GOLDEN ARMAZENADOS SOB DIFERENTES CONCENTRAÇÕES DE OXIGENIO'
}

\author{
LUCIANA KONDA DE AZEVEDO PINTO², MEIRE LELIS LEAL MARTINS ${ }^{3}$, \\ EDER DUTRA DE RESENDE ${ }^{4}$, JOSÉ TARCÍSIO LIMA THIÈBAUT ${ }^{5}$, MARCO ANTONIO MARTINS
}

RESUMO - Este trabalho foi realizado com o objetivo de avaliar o efeito de atmosferas controladas contendo diferentes concentrações de oxigênio sobre a atividade das enzimas $\beta$-galactosidase e pectina metilesterase, e sobre a cor da casca e a firmeza da polpa de mamões 'Golden'. Os frutos foram mantidos por 36 dias, nas seguintes atmosferas controladas: $1 \%$ de $\mathrm{O}_{2}$ e $0,03 \% \mathrm{CO}_{2}$ com adsorvedor de etileno, $3 \%$ de $\mathrm{O}_{2}$ e $0,03 \%$ de $\mathrm{CO}_{2}$ com adsorvedor de etileno, $5 \% \mathrm{O}_{2}$ e $0,03 \%$ de $\mathrm{CO}_{2}$ com adsorvedor de etileno e atmosfera ambiente sem adsorvedor de etileno. A UR e a temperatura foram mantidas entre $85-95 \%$ e a $13^{\circ} \mathrm{C}$, respectivamente. Os frutos estocados sob atmosfera de $1 \%$ de $\mathrm{O}_{2}$ e $0,03 \% \mathrm{CO}_{2}$ apresentaram retardamento nas atividades das enzimas $\beta$-galactosidase e pectina metilesterase comparado com os frutos estocados nas outras atmosferas avaliadas. Os frutos armazenados sob atmosfera de $1 \%$ de $\mathrm{O}_{2}$ e $0,03 \% \mathrm{O}_{2}$ também apresentaram atraso no desenvolvimento da cor da casca e amolecimento da polpa.

Termos para indexação: Carica papaya, atmosfera controlada, $\beta$-galactosidase, pectinametilesterase, firmeza de polpa.

\section{ACTIVITY OF PECTIN METHYLESTERASE AND $\beta$-GALACTOSIDASE ENZYMES IN 'GOLDEN' PAPAYA STORED UNDER DIFFERENT OXYGEN CONCENTRATIONS}

\begin{abstract}
This study was carried out with the objective to evaluate the effect of controlled atmospheres containing different concentration of oxygen on the activity of $\beta$-galactosidase and pectinmethylesterase enzymes, on the skin color and pulp firmness in 'Golden' papaya. The fruits were kept for 36 days under the following controlled atmospheres: $1 \%$ of $\mathrm{O}_{2}$ and $0.03 \% \mathrm{CO}_{2}$ with ethylene absorber, $3 \%$ of $\mathrm{O}_{2}$ and $0.03 \%$ of $\mathrm{CO}_{2}$ with ethylene absorber, $5 \% \mathrm{O}_{2}$ and $0.03 \%$ of $\mathrm{CO}_{2}$ with ethylene absorber and environmental atmosphere without ethylene absorber. Relative humidity was set at the range $85-95 \%$ and temperature maintained at $13^{\circ} \mathrm{C}$. Fruit stored under atmospheres of $1 \%$ of $\mathrm{O}_{2}$ and $0.03 \% \mathrm{CO}_{2}$ had a $\beta$-galactosidase and pectimethylesterase activities delayed compared with the fruits storage under the other atmospheres evaluated. There was also, a delay in the development of color and pulp softening in fruits stored under atmospheres of $1 \%$ of $\mathrm{O}_{2}$ and $0.03 \% \mathrm{O}_{2}$.
\end{abstract}

Index terms: Carica papaya, controlled atmosphere, $\beta$-galactosidase, pectinmethylesterase, softening.

\footnotetext{
${ }^{1}$ (Trabalho 222-12). Recebido em: 05-07-2012. Aceito para publicação em: 29-11-2012. Extraído da Tese de Doutorado em Produção Vegetal da primeira autora

${ }^{2}$ Doutora em Produção Vegetal, Laboratório de Tecnologia de Alimentos (LTA), CCTA, UENF, Campos dos Goytacazes - RJ, CEP 28013-602. E-mail: lukonda@yahoo.com

${ }^{3}$ Professora Associada, LTA, CCTA, UENF. E-mail: meire@uenf.br (* autor para correspondência)

${ }^{4}$ Professor Associado, LTA, CCTA, UENF. E-mail: eresende@uenf.br

${ }^{5}$ Professor Associado, Laboratório de Engenharia Agrícola, CCTA, UENF. E-mail: jtt1512@uenf.br

${ }^{6}$ Professor Associado, Laboratório de Solos, CCTA, UENF. E-mail: marco@uenf.br
} 


\section{INTRODUÇÃO}

$\mathrm{O}$ amolecimento é um dos principais fatores que determinam a qualidade da vida útil dos frutos e acredita-se ser o resultado da degradação da parede celular (BRUMMELL 2006). Algumas hidrolases de parede celular aumentam sua atividade durante o amadurecimento, e este aumento é coincidente com o amolecimento do fruto (THUMDEE et al., 2010).

Durante o amolecimento, ocorrem mudanças na estrutura da pectina, hemicelulose e celulose, responsáveis pelas alterações da estrutura da parede celular (PAULL et al., 1999). Devido à complexidade dessa estrutura, um conjunto de enzimas é responsável pela hidrólise da parede celular, o que resulta no amaciamento dos frutos. Enzimas pectinolíticas, como a pectina metilesterase e as galactosidases, promovem a solubilização e a despolimerização da pectina. A enzima pectina metilesterase (PME, EC 3:1.1.11) catalisa a hidrólise do grupo metila da pectina, formando pectina de baixa metoxilação e liberando metanol (ARBAISAH et al., 1996), disponibilizando substrato para a ação das poligalacturonases $(\mathrm{PG})$.

A $\beta$-galactosidase ( $\beta$-Gal, EC 3.2.1.23) é uma enzima hidrolítica que age em conjunto com as enzimas pectolíticas (PG e PME) e pode contribuir para o amaciamento de frutos (LIMA et al., 2006). Sua ação consiste na quebra das ligações cruzadas do tipo 1,4 $\beta$-galactosídicas entre os polímeros pécticos e de hemicelulose (BARBOSA et al., 2007).

Uma forma de aumentar a vida pós-colheita dos frutos é a utilização da atmosfera controlada durante o armazenamento dos mesmos, que consiste na redução dos níveis de $\mathrm{O}_{2}$ ou elevação dos níveis de $\mathrm{CO}_{2}$. Concentrações elevadas de $\mathrm{CO}_{2}$ mantêm maior firmeza de polpa durante o armazenamento, inibindo a respiração do fruto (BRACKMANN et al., 2000; LIU et al., 2004).

Segundo Lazan et al. (1995), as principais enzimas envolvidas com a hidrólise da parede celular, e o consequente amaciamento da polpa do mamão, são a poligalacturonase, a pectina metilesterase e a $\beta$-galactosidase. Neste trabalho, investigou-se o efeito da redução da concentração de $\mathrm{O}_{2}$ sobre a atividade das enzimas $\beta$-galactosidase e pectina metilesterase, correlacionando com a cor da casca e a firmeza da polpa, durante o armazenamento do mamão cv. Golden, tendo em vista a carência de informações bioquímicas dos frutos desta cultivar mantidos sob condições de atmosfera controlada.

\section{MATERIAL E MÉTODOS}

Matéria-prima e preparo das amostras

Frutos de mamoeiro do grupo Solo, variedade Golden, apresentando aproximadamente $15 \%$ de cor amarela na casca (uma pinta) e peso médio de $500 \mathrm{~g}$, foram selecionados na linha de embalagem da $\mathrm{Ca}$ liman Agrícola S.A. (Linhares-ES). Os frutos, após passarem pelo banho hidrotérmico $\left(48^{\circ} \mathrm{C} / 20 \mathrm{~min}\right)$ e banho com fungicida (2 min), foram transportados sob refrigeração a $10^{\circ} \mathrm{C}$, até o Laboratório de Tecnologia de Alimentos da Universidade Estadual Norte Fluminense. No laboratório, os frutos passaram por uma solução de hipoclorito de sódio, $100 \mathrm{mg} \mathrm{mL}^{-1}$, antes de serem acondicionadas nas minicâmaras. Os experimentos foram realizados até 24 h após a colheita na empresa.

\section{Armazenamento dos frutos}

Os frutos foram armazenados em minicâmaras de atmosfera controlada com volume de 140 litros, inseridas dentro de uma câmara frigorífica de $27,45 \mathrm{~m}^{3}$ regulada para uma temperatura de $13^{\circ} \mathrm{C}$. As minicâmaras foram conectadas por tubulações plásticas a um sistema de controle automático da concentração do oxigênio e do gás carbônico. Os frutos foram acondicionados em estantes de aço inox perfurado e, após o fechamento das minicâmaras, foi feita a instalação das atmosferas investigadas, através da injeção de nitrogênio $\left(\mathrm{N}_{2}\right)$ até a obtenção da concentração de $\mathrm{O}$, desejada.

As condições de estocagem avaliadas foram: $1 \%$, $3 \%$ e $5 \%$ de $\mathrm{O}_{2}$ combinadas com $0,03 \%$ de $\mathrm{CO}_{2}$ e em atmosfera ambiente. Para a manutenção constante das concentrações do $\mathrm{O}_{2}$ e $\mathrm{CO}_{2}$, que se modificaram em função do processo respiratório dos frutos, foi realizada diariamente uma análise e correção das pressões parciais destes gases. Esta análise foi feita com um controlador automático, marca Kronenberger-Climasul. $\mathrm{O} \mathrm{O}_{2}$ consumido foi reposto através da injeção de ar atmosférico nas minicâmaras. $\mathrm{O} \mathrm{CO}_{2}$ foi adsorvido por uma solução de hidróxido de sódio saturado $(30 \%)$, contido em um tanque hermeticamente fechado, através do qual circulavam os gases das minicâmaras. $\mathrm{O}$ etileno foi totalmente adsorvido do ambiente de estocagem por uma coluna de adsorção contendo permanganato de potássio, para minimizar o efeito autocatalítico que acelera o amadurecimento.

Os mamões foram armazenados por um período de 36 dias, sendo que, nos primeiros 6 dias, foram retirados 5 frutos por tratamento a cada 2 dias. Após esse período, o intervalo passou para 6 dias. As análises realizadas nos frutos foram: coloração da 
casca, determinação da firmeza da polpa e atividade das enzimas, pectina metilesterase e b-galactosidase.

\section{Medidas da firmeza da polpa, coloração da casca e ensaios enzimáticos}

Os frutos foram divididos transversalmente na região equatorial e, posteriormente, foi realizado um corte longitudinal, separando o lado do fruto que ficou exposto à radiação solar durante o período após antese (lado exposto ao sol) e o lado que ficou voltado para o caule do mamoeiro (lado não exposto ao sol). As extremidades foram descartadas. As análises físico-químicas e enzimáticas foram realizadas nas amostras retiradas da metade externa do mesocarpo, do lado exposto ao sol, conforme metodologia descrita por Resende et al. (2003).

A coloração da casca dos frutos foi determinada utilizando um colorímetro de Hunter, (Hunterlab MiniScan XE Plus, USA) calibrado com padrões de placas preta e branca. Utilizou-se o padrão de iluminação D65 com ângulo de $10^{\circ}$. Realizaram-se quatro leituras em pontos equidistantes da região equatorial do fruto. Os resultados foram caracterizados pelas medidas do ângulo hue $\left(\right.$ hue $\left.^{0}\right)$. A evolução do amadurecimento foi avaliada pelos valores de ângulo hue entre $120^{\circ}$ e $60^{\circ}$, que indicam a mudança da cor verde para a amarela da casca.

As medidas de firmeza da polpa foram realizadas com auxílio de um penetrômetro digital de bancada (Turoni, modelo 53205) com sonda de $8 \mathrm{~mm}$ de diâmetro. Os frutos foram partidos transversalmente na região equatorial, e as medidas, realizadas em dois pontos equidistantes na metade externa (próxima da casca), na região do fruto exposta ao sol. Os resultados representam a força em Newton necessária para penetrar $11 \mathrm{~mm}$ na polpa.

Para a realização dos ensaios enzimáticos, amostras foram retiradas dos mamões com auxílio de um amostrador cilíndrico com diâmetro de $2 \mathrm{~cm}$, pesadas em balança semianalítica Gehaka, modelo BG 2000, embaladas em papel-alumínio e imediatamente congeladas em freezer vertical da marca Consul.

A extração da PME foi realizada de acordo com o procedimento descrito por Hagerman e Austin (1986). Amostras de $5 \mathrm{~g}$ de polpa de mamão foram homogeneizadas (Turratec, TECNAL), em $40 \mathrm{~mL}$ de uma solução de $\mathrm{NaCl}$ 1,0 M, pH 7,5, contendo $1,0 \%(\mathrm{p} / \mathrm{v})$ de polivinilpolipirrolidona (PVPP). Esta solução foi centrifugada a $15.000 \mathrm{~g}$, durante 30 minutos, em centrífuga Eppendorf, modelo $5415 \mathrm{C}$. No sobrenadante obtido, foi determinada a atividade da PME.

Para a determinação da atividade da PME, 0,8
$\mathrm{mL}$ do extrato enzimático foi adicionado a $2,0 \mathrm{~mL}$ de uma solução de pectina a $0,5 \%(\mathrm{p} / \mathrm{v})$, contendo $0,15 \mathrm{~mL}$ de $0,01 \%(\mathrm{p} / \mathrm{v})$ de azul de bromotimol (3,3-dibromotimossulfenolftaleína), $\mathrm{pH}$ 7,5 e 0,2 $\mathrm{mL}$ de $\mathrm{NaCl} 1 \mathrm{M}$. Esta solução foi incubada a $80^{\circ} \mathrm{C}$, durante 1 minuto, e o decréscimo da absorbância a $620 \mathrm{~nm}$ monitorada em um espectrofotômetro, por um período de 1 minuto, com leituras a intervalos de 10 segundos. A variação da absorvância por minuto foi convertida para $\mu \mathrm{mol}$ de ácido produzido por minuto, através de uma curva de calibração, utilizando o ácido galacturônico como padrão. Uma unidade da PME foi definida como a quantidade de enzima que libera $1 \mu \mathrm{mol}$ de ácido galacturônico por minuto, por volume.

Para a extração da b-galactosidase, dez gramas da polpa foram homogeneizadas em Turratec da marca TECANL (Turrax) com $30 \mathrm{~mL}$ de solução tampão de acetato de sódio $50 \mathrm{mM}$, pH 5,0 gelado, contendo $1 \mathrm{M}$ de $\mathrm{NaCl}$ e $10 \%$ de polivinilpolipirrolidione (PVPP), durante 6 minutos, a $4^{\circ} \mathrm{C}$. Após 2 horas de repouso a $4^{\circ} \mathrm{C}$, esta solução foi filtrada em 2 camadas de tecido de algodão, e o filtrado centrifugado, em uma centrífuga refrigerada (Hermele $\mathrm{Z}$ $382 \mathrm{~K}$, Alemanha) a $15.000 \mathrm{~g}$, por 30 minutos, a $4^{\circ} \mathrm{C}$ (VICENTE et al., 2005).

A atividade da b-galactosidase foi determinada incubando $1,5 \mathrm{~mL}$ de $50 \mathrm{mM}$ de tampão acetato

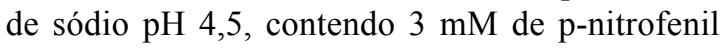
b-D-galactopiranosídeo com $0,5 \mathrm{~mL}$ do extrato enzimático, a $55^{\circ} \mathrm{C}$, durante 20 minutos. A reação foi paralisada, retirando-se alíquotas de $0,150 \mathrm{~mL}$, e

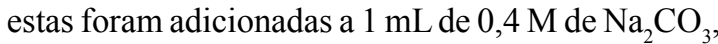
a fim de paralisar a reação A coloração desenvolvida foi medida através de espectrofotômetro SHIMADZU UV-mini 1240, utilizando-se de comprimento de onda de $410 \mathrm{~nm}$. Uma unidade da enzima foi definida como a variação da absorbância por minuto. Os níveis da atividade enzimática foram expressos em unidade por volume $(\mathrm{U} / \mathrm{mL})$.

\section{tatística}

Delineamento experimental e análise es-

Os fatores porcentagem de $\mathrm{O}_{2}$ e tempo em dias foram analisados segundo o delineamento inteiramente casualizado, ao nível de 5\% de probabilidade. Posteriormente, em cada nível de $\mathrm{O}_{2}$, foi feita uma regressão polinomial da característica em questão, em função do tempo em dias. 


\section{RESULTADOS E DISCUSSÃO}

A atividade da enzima $\beta$-Gal dos frutos de mamoeiro armazenados em atmosfera controlada a $1 \%, 3 \%$ e $5 \%$ de $\mathrm{O}_{2}$ e em atmosfera ambiente está mostrada nas Figuras $1 \mathrm{~A}$ e 1C, respectivamente. Um aumento da atividade da $\beta$-Gal foi observado até o $30^{\circ}$ dia de armazenamento, para todos os tratamentos, embora esse aumento não tenha sido gradual (Figura 1A). Resultados semelhantes foram encontrados por Karakurt e Huber (2003), que observaram um aumento da atividade da $\beta$-Gal durante a estocagem de frutos de mamoeiro 'Sunrise Solo', minimante processados, e de frutos intactos mantidos a $5^{\circ} \mathrm{C}$. Registros do aumento da atividade desta enzima durante o amadurecimento foram também observados em graviola (LIMA et al., 2006), pera (MWANIKI et al., 2005) e mamão (LAZAN et al., 1995). Após 30 dias de armazenamento, a atividade da $\beta$-Gal apresentou uma queda até o final do período da estocagem.

Os valores da atividade da $\beta$-Gal ao longo do período de armazenamento variaram de acordo com a concentração de $\mathrm{O}_{2}$ utilizada. Nota-se que, nos primeiros períodos do armazenamento ( 6 dias), a atividade da $\beta$-Gal foi maior quando se empregaram $5 \%$ de $\mathrm{O}_{2}$, e menor quando uma atmosfera de $1 \%$ de $\mathrm{CO}_{2}$ foi utilizada. A atividade da $\beta$-Gal foi menor na atmosfera com $1 \%$ de $\mathrm{O}_{2}$ até 18 dias de estocagem. No período final do armazenamento, a maior atividade da enzima foi observada no tratamento com $1 \%$ de $\mathrm{O}_{2}$. Estes resultados indicaram que a atmosfera de $1 \%$ de $\mathrm{O}_{2}$ retardou a atividade da $\beta$-Gal no início do armazenamento sem, contudo, deixar de estimular sua síntese no final do período de armazenamento. Em mamões, evidências indicam que a $\beta$-galactosidase pode contribuir significativamente na modificação da pectina e da hemicelulose, contribuindo, consequentemente, para o amolecimento do fruto (LAZAN et al., 1995).

O comportamento da enzima nos mamões armazenados em atmosfera ambiente (Figura 1C) foi semelhante ao encontrado para os mamões armazenados em atmosfera controlada (Figura 1A). Um aumento da atividade enzimática foi observado até o $30^{\circ}$ dia de armazenamento, embora o aumento não tenha sido gradual. Entre o $12^{\circ}$ e o $18^{\circ}$ dia de armazenamento, a atividade enzimática apresentou uma queda similar à observada nos mamões armazenados em atmosfera com $1 \%$ e $5 \%$ de $\mathrm{O}_{2}$

A atividade da enzima PME dos frutos de mamoeiro estocados em atmosfera controlada a $1 \%, 3 \%$ e $5 \%$ de $\mathrm{O}_{2}$ e em atmosfera ambiente está mostrada nas Figuras 1B e 1D, respectivamente. A atividade da PME dos mamões armazenados em atmosfera controlada com $1 \%$ de $\mathrm{O}_{2}$ foi menor até o $18^{\circ}$ dia de armazenamento, em comparação com as demais concentrações estudadas (Figura 1B). Nesse tratamento, a atividade da PME aumentou gradualmente até o $30^{\circ}$ dia e então decresceu. Comportamento semelhante da atividade da PME foi observado para os mamões armazenados em atmosfera com 3\% e $5 \%$ de $\mathrm{O}_{2}$. A atividade desta enzima aumentou até o $6^{\circ}$ dia de armazenamento, posteriormente decresceu até o $18^{\circ}$ dia de armazenamento e então aumentou novamente até o $30^{\circ}$ dia e finalmente caiu. $\mathrm{O}$ valor máximo da atividade da PME $(365,42 \mathrm{U} / \mathrm{mL})$ foi encontrado no $30^{\circ}$ dia de armazenamento para os mamões estocados em atmosfera com $3 \%$ de $\mathrm{O}_{2}$. Este histórico é similar àquele observado por Pinto et al. (2011), exceto no início do amadurecimento. Isto pode ter ocorrido devido ao atraso na operação com os frutos até o fechamento das minicâmaras de atmosfera controlada.

Fonseca et al. (2006) relataram que a atividade da enzima pectina metilesterase, indiferentemente do sistema de controle da atmosfera de armazenamento, utilizando a mesma temperatura de $10^{\circ} \mathrm{C}$, apresentou comportamento cúbico no mamão 'Sunrise Solo', com valores máximos entre o sexto e o oitavo dia de avaliação. Já para o mamão 'Golden', estes autores encontraram que a atividade da PME apresentou comportamento quadrático, com valores máximos entre o quarto e o sexto dia de avaliação. Em uvas 'Kyoho' armazenadas nas atmosferas com $4 \%$ de $\mathrm{O}_{2}+9 \%$ de $\mathrm{CO}_{2}, 4 \%$ de $\mathrm{O}_{2}+30 \%$ de $\mathrm{CO}_{2} \mathrm{e}$ em atmosfera-controle, foi verificado que não houve diferença na atividade da enzima PME (DENG et al., 2007). Entretanto, em maçãs 'Gala' armazenadas em atmosfera ambiente por oito meses, a atividade da PME foi menor quando comparada com as frutas armazenadas sob atmosferas de $1,0 \mathrm{KPa} \mathrm{O}_{2}+2,5$ $\mathrm{CO}_{2} ; 1,0 \mathrm{KPaO}_{2}+2,0 \mathrm{CO}_{2} ; 0,8 \mathrm{KPa} \mathrm{O}_{2}+2,0 \mathrm{CO}_{2}$; e $0,8 \mathrm{KPa} \mathrm{O}_{2}+2,5 \mathrm{KPa} \mathrm{CO}_{2}$ (LUNARDI et al., 2004). De acordo com Lima et al. (2006), a atividade da PME pode diminuir, permanecer constante ou aumentar durante a maturação, dependendo do fruto e do método de extração. Um Comportamento similar da atividade da PME foi observado nos mamões armazenados em atmosfera ambiente (Figura 1D). A atividade da enzima aumentou até o $6^{\circ}$ dia, apresentou uma queda até o $18^{\circ}$ dia e posteriormente aumentou até o $30^{\circ}$ dia e então caiu novamente.

Os resultados das medidas de firmeza dos frutos de mamoeiro armazenados em atmosfera controlada a $1 \%, 3 \%$ e $5 \%$ de $\mathrm{O}_{2}$ e em atmosfera ambiente estão mostrados nas Figuras $2 \mathrm{~A}$ e 2C. Os mamões armazenados em atmosfera com $1 \%$ de $\mathrm{O}_{2}$ apresentaram maior firmeza durante $\mathrm{o}$ armazenamen- 
to. Estes resultados são similares aos encontrados por Martins (2005), que verificou o enrijecimento da polpa de mamão 'Golden', atribuído ao distúrbio fisiológico do mamão armazenado em atmosfera controlada contendo $1 \% \mathrm{O}_{2}$ e $10 \% \mathrm{CO}_{2}$. Segundo o mesmo autor, as medidas de firmeza de polpa do mamão apresentam um grande coeficiente de variação, tornando os modelos de regressão dos dados com um baixo coeficiente de determinação, conforme verificado também no presente trabalho.

Com 12 dias, os frutos estocados a $1 \%, 3 \% \mathrm{e}$ 5\% apresentaram valores de firmeza de 81,76; 32,74 e $31,75 \mathrm{~N}$, respectivamente. Esta menor perda de firmeza observada nos frutos armazenados com $1 \%$ de $\mathrm{O}_{2}$ pode ser explicada pela menor atividade da $\beta-\mathrm{Gal}$ e da PME encontrada nos períodos iniciais de estocagem dos frutos (Figuras 1A e 1B). Estes resultados demonstram a importância das enzimas PME e $\beta$-Gal no processo de amolecimento do mamão e a eficácia do tratamento, em que foi utilizada a atmosfera com $1 \%$ de $\mathrm{CO}_{2}$ no controle da atividade destas enzimas. Segundo Taiz e Zeiger (2006), o etileno é o hormônio que sinaliza a síntese das enzimas envolvidas com a hidrólise dos componentes da parede celular. Isto possivelmente explicaria a menor atividade das enzimas PME e $\beta$-Gal na condição de maior supressão de $\mathrm{O}_{2}$, tendo em vista que a síntese de etileno é dependente da presença de oxigênio.

Uma redução da firmeza e um aumento da atividade da $\beta$-galactosidase foram observados em manga cv. Harumanis por Ali et al. (1995). Segundo estes autores, entre as glicosidases estudadas, a $\beta$-Gal pareceu ser a mais significativa. A atividade desta enzima aumentou em paralelo com o aumento do amolecimento do tecido durante o amadurecimento da fruta. Os mamões armazenados em atmosfera ambiente apresentaram uma perda da firmeza (Figura 2C) acompanhada com o aumento da atividade $\beta$-Gal e PME (Figuras 1C e 1D), mostrando a correlação dessas enzimas no processo inicial de amolecimento dos frutos de mamoeiro.

Os frutos de mamoeiro armazenados a $1 \%$ de $\mathrm{O}_{2}$ mantiveram a coloração verde $\left(\mathrm{H}=100,09^{\circ}\right)$ até o $12^{\circ}$ dia de armazenamento, enquanto os frutos armazenados a $3 \%$ e a $5 \%$ apresentaram valores de média do ângulo hue 90,61 e $89,63^{\circ}$, respectivamente, indicando uma coloração menos verde (Figura 2B). Estes resultados mostram que a utilização da atmosfera com $1 \% \mathrm{de}_{2}$ reteve mais o desenvolvimento da cor da casca, indicador de estádio de maturação. Após o $12^{\circ}$ dia de armazenamento, os mamões estocados em atmosfera com $1 \%$ de $\mathrm{O}_{2}$ apresentaram valores do ângulo hue superiores aos encontrados para as outras atmosferas. Portanto, o armazenamento dos mamões em atmosfera com $1 \%$ de $\mathrm{O}_{2}$ não prejudicou a síntese de carotenoides, apenas retardou seu desenvolvimento, fornecendo indícios de que o processo de amadurecimento possa ter sido retardado. Resultados similares foram encontrados por Fonseca et al. (2006), que observaram diferentes índices de coloração da casca de mamões 'Sunrise Solo' armazenados sob diferentes atmosferas. Segundo estes autores, os mamões apresentaram taxas de desenvolvimento fisiológico distintas entre as atmosferas estudadas. Brackmann et al. (2000) verificaram manutenção da coloração de fundo ligeiramente mais verde, logo após a abertura das câmaras, em maçãs 'Gala', em armazenamento sob 2,3\% de $\mathrm{O}_{2}$, associado a $13,6 \%$ de $\mathrm{CO}_{2}$, durante 5 dias, seguidos de $1,5 \%$ de $\mathrm{O}_{2}$ e de $3,0 \%$ de $\mathrm{CO}_{2}$, em período total de oito meses. Contudo, após sete dias em temperatura ambiente, a coloração dos frutos evoluiu rapidamente, não existindo mais diferenças. Os mamões armazenados em atmosfera ambiente apresentaram comportamento semelhante aos frutos conservados em atmosfera controlada a 3 e $5 \%$ de $\mathrm{O}_{2}$ (Figura 2D). 

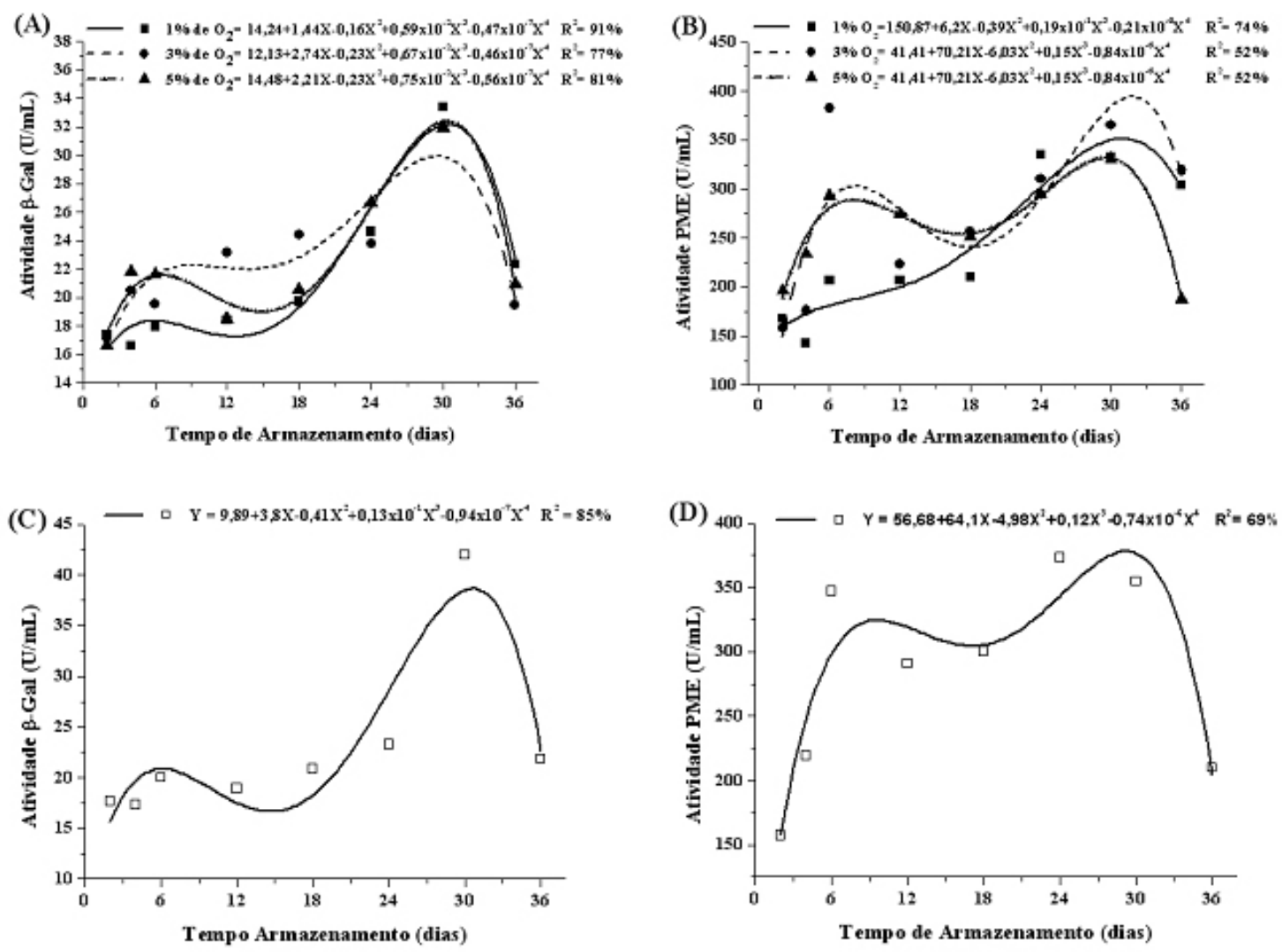

FIGURA 1 - Atividade das enzimas $\beta$-Gal (A) e PME (B) em mamões 'Golden' armazenados a 1\% (ロ), $3 \%(\bullet)$ e $5 \%(\boldsymbol{\Delta})$ de $\mathrm{O}_{2}$ e (口) em atmosfera ambiente (C, D), durante 36 dias, sob temperatura de $13^{\circ} \mathrm{C}$ e $85-95 \%$ UR. 

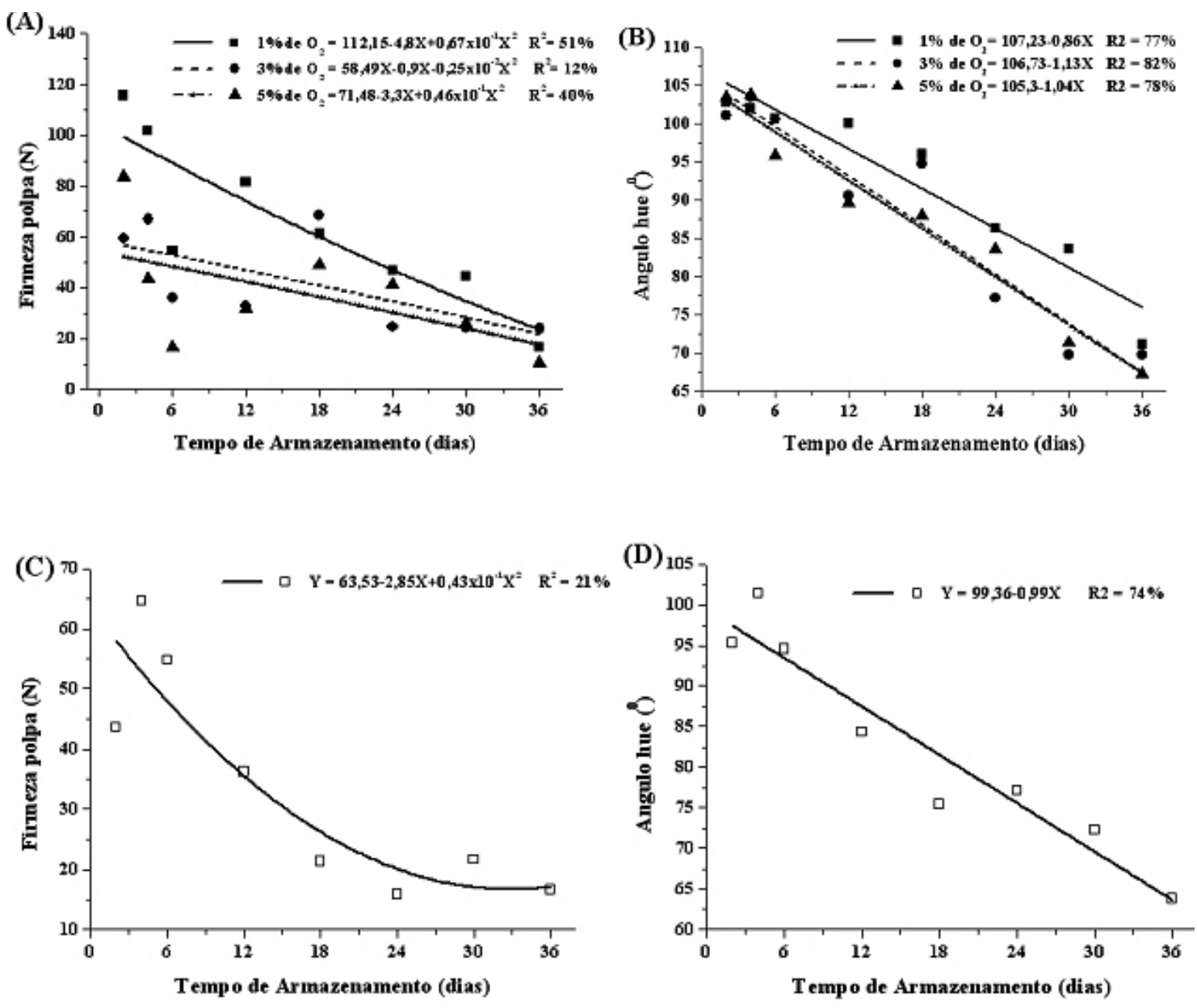

FIGURA 2 - Firmeza da polpa (A) e Ângulo hue (B) de mamões "Golden" armazenados a 1\% (匹), 3\% $(\bullet)$ e $5 \%(\boldsymbol{\Delta})$ de $\mathrm{O}_{2}$ e $(\square)$ em atmosfera ambiente $(\mathrm{C}, \mathrm{D})$, durante 36 dias, sob temperatura de $13^{\circ} \mathrm{C}$ e $85-95 \%$ UR.

\section{CONCLUSÃO}

Mamões ‘Golden' armazenados sob condições de atmosfera controlada, contendo $1 \%$ de $\mathrm{O}_{2}$ e $0,03 \%$ de $\mathrm{O}_{2}$, apresentam redução na atividade das enzimas $\beta$-galactosidase e pectina metilesterase nos períodos iniciais da estocagem. Nestas mesmas condições, é observada menor redução da firmeza dos frutos e atraso no aparecimento da cor amarela da casca, indicando que o processo de amadurecimento dos frutos é retardado.

\section{AGRADECIMENTOS}

Os autores agradecem à FINEP, CNPq e à FAPERJ, pelo financiamento da pesquisa, e à CALIMAN AGRÍCOLA S.A., pela parceria no projeto FRUTIMAMÃO.

\section{REFERÊNCIAS}

ALI, Z. M.; ARMUGAN, S. ; LAZAN, H. $\beta$-galactosidase and its significance in ripening mango fruit. Phytochemistry, New York, v. 38, p. 1109-1114, 1995.

ARBAISAH, Z.M.; ASBI, B.A. ; JUNAINAH, A.H.; JAMILAH, B. Determination of optimum conditions for pectinesterase extraction from soursop fruit (Anona muricata) using response surface methodology. Food Chemistry, New York, v. 55, p. 289-292, 1996.

BARBOSA, G. K. C.; MIRANDA, M. R. A.; MENDES, L. G. Estudo inicial da beta-galactosidase da parede celular da polpa de sapoti (Manilkara sapota L. Von Royen) maduro. In: CONGRESSO BRASILEIRO DE QUÍMICA, 47., 2007. Anais... Natal: ABQ-RN, 2007. 
BRACKMANN, A.; WACLAWOSKY, A.J.; BALZ, $\mathrm{G}$. Tratamentos com altas concentrações de $\mathrm{CO} 2 \mathrm{em}$ maçãs cv. Gala antes do armazenamento em atmosfera controlada. Revista Brasileira de Fruticultura, Jaboticabal, v. 22, p. 82-85, 2000.

BRUMMELL, D.A. Cell wall disassembly in ripening fruit. Functional Plant Biology, Collingwood, v. 33, p.103-119, 2006.

DENG, Y.; WU, Y.; LI, Y. Effects of high $\mathrm{CO}_{2}$ and low $\mathrm{O}_{2}$ atmospheres on the berry drop of "Kyoho" grapes. Food Chemistry, New York, v. 100, p. 768$773,2007$.

FONSECA, M. J. O.; LEAL, N.; CENCI, S. A.; CECON, P. R.; SMITH, R. E. B. Conservação pós-colheita de mamão 'Sunrise Solo' e 'Golden' em atmosfera controlada. Revista Brasileira de Armazenamento, Viçosa, v. 31,p. 154-161, 2006.

HAGERMAN, A. E.; AUNSTIN, P. J. Continuous Spectrophotometric Assay for Plant Pectin Methyl Esterase. Journal Agricultural Food Chemistry, Washington, v. 34, p.440-444, 1986.

KARAKURT, Y.; HUBER, D. J. Activities of several membrane and cell-wall hydrolyses, ethylene biosynthetic enzymes, and cell wall polyronide degradation during low-temperature storage of intact and fresh-cut papaya (Carica papaya) fruit. Postharvest Biology and Technology, Amsterdam, v. 18, p. $219-229,2003$.

LAZAN, H.; SELAMAT, M. K.; ALI, Z. M. $\beta$-Galactosidase, polygalacturonase and pectinesterase in differential softening and cell wall modification during papaya fruit ripening. Physiologia Plantarum, Sweden, v. 95, p. 106-112, 1995.

LIMA, M. A. C.; ALVES, R. E.; FILGUEIRAS, H. A. C. Mudanças relacionadas ao amaciamento da graviola durante a maturação pós-colheita, Pesquisa Agropecuária Brasileira, Brasília, v. 41, p.17071713,2006

LIU, S.; YANG Y.; MURAYAMA, H.; TAIRA, S.; FUKUSHIMA, T. Effects of $\mathrm{CO}_{2}$ on respiratory metabolism in ripening banana fruit. Postharvest Biology and Technology, Amsterdam, v. 33, n.1, p. 27-34, 2004

LUNARDI, R.; BRACKMANN, A.; NEUWALD, D. A.; ZANATTA, J.F.; SILVA, J. A.; ROMBALDI, C. V. Avaliação da suculência em maçãs 'Gala" armazenadas em atmosfera controlada, em função de diferentes pressões parciais de $\mathrm{O} 2$ e $\mathrm{CO} 2$. Ciência e Agrotecnologia, Lavras, v, 28, p. 95-101, 2004.
MARTINS, D. R. Qualidade pós-colheita do mamão armazenado sob refrigeração em condições de atmosfera controlada. 2005. 102 f. Dissertação (Mestrado em Produção Vegetal) - Campos dos Goytacazes, Universidade Estadual do Norte Fluminense Darcy Ribeiro Campos dos Goytacazes, 2005.

MWAMIKI, M. W.; MATHOOKO, F. M.; MAATSUZAKI, M.; HIWASA, K.; TATEISHI, A.; USHIJIMA, K.; NAKANO, R.; INABA, A.; KUBO, Y. Expression characteristic of seven members of $\beta$-galactosidase gene family in 'La France" pear (Pyrus communis L.) fruit during growth and their regulation by 1-methylccyclopropene during postharvest ripening. Postharvest Biology and Technology, Amsterdam, v. 36, p. 253-263, 2005.

PAULL, R. E.; GROSS, K.; QIU, Y. Changes in papaya cell wall during fruit ripening. Postharvest Biology and Technology, Amsterdam, v. 16, p. 7989, 1999.

PINTO, L. K. A.; MARTINS, M. L. L.; RESENDE, E. D.; THIÉBAUT, J. T. L. Atividade da pectina metilesterase e da $\beta$-Galactosidade durante o amadurecimento do mamão cv. Golden. Revista Brasileira de Fruticultura, Jaboticabal, v. 33, n. 3, p. 713-722, 2011.

RESENDE, E. D.; CARLOS, L. A.; VITORAZI, L.; OLIVEIRA, V. V. Desenvolvimento e avaliação de uma metodologia de amostragem de frutos de mamoeiro (Carica papaya L.). In: REUNIÃO DE PESQUISA DO FRUTIMAMÃO NO NORTE FLUMINENSE, 1., Campos dos Goytacazes, 2003. Anais... CD-ROM

TAIZ, L.; ZEIGER, E. Plant physiology. 4. ed. Sunderland: Sinauer Associates, 2006. 764 p.

THUMDEE, S.; MANENOI, A.; CHEN, N. J.; PAULL, R. E. Papaya Fruit Softening: Role of Hydrolyses. Tropical Plant Biology, Brasília, v. 3, p. 98-109, 2010.

VICENTE, A. R.; COSTA, M. L.; MARTINEZ, G. A.; CHAVES, A. R.; CIVELLO, P. M. Effect of heat treatment on cell wall degradation and softening in strawberry fruit. Postharvest Biology and Technology, Amsterdam, v. 38, p. 213-222, 2005. 